\title{
A multivariate logistic regression equation to screen for dysglycaemia: development and validation
}

\author{
B. P. Tabaei*, M. M. Engelgaut and W. H. Herman* $\neq$
}

Department of *Internal Medicine, University of Michigan Health System, Ann Arbor, Ml, tDivision of Diabetes Translation, Centers for Disease Control and Prevention, Atlanta, Georgia and \#Department of Epidemiology, University of Michigan Health System, Ann Arbor, MI, USA

Accepted 9 June 2004

\begin{abstract}
Aims To develop and validate an empirical equation to screen for dysglycaemia [impaired fasting glucose (IFG), impaired glucose tolerance (IGT) and undiagnosed diabetes].
\end{abstract}

Methods A predictive equation was developed using multiple logistic regression analysis and data collected from 1032 Egyptian subjects with no history of diabetes. The equation incorporated age, sex, body mass index (BMI), post-prandial time (self-reported number of hours since last food or drink other than water), systolic blood pressure, high-density lipoprotein (HDL) cholesterol and random capillary plasma glucose as independent covariates for prediction of dysglycaemia based on fasting plasma glucose $(\mathrm{FPG}) \geq 6.1 \mathrm{mmol} / \mathrm{l}$ and/or plasma glucose $2 \mathrm{~h}$ after a 75 -g oral glucose load $(2-\mathrm{h} \mathrm{PG}) \geq 7.8 \mathrm{mmol} / \mathrm{l}$. The equation was validated using a cross-validation procedure. Its performance was also compared with static plasma glucose cut-points for dysglycaemia screening.

Results The predictive equation was calculated with the following logistic regression parameters: $P=1+1 /\left(1+\mathrm{e}^{-\mathrm{X}}\right)=$ where $\mathrm{X}=-8.3390+0.0214$ (age in years) + 0.6764 (if female) $+0.0335\left(\mathrm{BMI}\right.$ in $\left.\mathrm{kg} / \mathrm{m}^{2}\right)+0.0934$ (post-prandial time in hours) + 0.0141 (systolic blood pressure in $\mathrm{mmHg}$ ) -0.0110 ( $\mathrm{HDL}$ in $\mathrm{mmol} / \mathrm{l})+0.0243$ (random capillary plasma glucose in $\mathrm{mmol} / \mathrm{l}$ ). The cut-point for the prediction of dysglycaemia was defined as a probability $\geq 0.38$. The equation's sensitivity was $55 \%$, specificity $90 \%$ and positive predictive value (PPV) $65 \%$. When applied to a new sample, the equation's sensitivity was $53 \%$, specificity $89 \%$ and PPV $63 \%$.

Conclusions This multivariate logistic equation improves on currently recommended methods of screening for dysglycaemia and can be easily implemented in a clinical setting using readily available clinical and non-fasting laboratory data and an inexpensive hand-held programmable calculator.

Diabet. Med. 22, 599-605 (2005)

Keywords capillary glucose, impaired fasting glucose, impaired glucose tolerance, risk factors, screening, undiagnosed diabetes

Abbreviations EPV, events per variable; FPG, fasting plasma glucose; HDL, high-density lipoprotein; IFG, impaired fasting glucose; IGT, impaired glucose tolerance; LDL, low-density lipoprotein; OAPR, odds of being affected given a positive result; PPV, positive predictive value
Correspondence to: William H. Herman MD MPH, University of Michigan Health System, Division of Endocrinology and Metabolism, 1500 East Medical Center Drive, 3920 Taubman Center, Ann Arbor, Ml 48109-0354, USA. E-mail: wherman@umich.edu

\section{Introduction}

Recent studies have demonstrated that lifestyle and medication interventions can delay or prevent progression from impaired glucose tolerance (IGT) to Type 2 diabetes [1-5]. Despite the 
lack of randomized controlled clinical trials, there is also growing evidence that earlier detection of Type 2 diabetes, improved glycaemic control and intensified risk factor management may result in clinically important improvements in diabetes-related morbidity and mortality [6,7]. Unfortunately, there is no consensus as to the most effective, efficient and cost-effective means to screen for dysglycaemia defined as impaired fasting glucose (IFG), IGT and previously undiagnosed diabetes. Ideally, any screening test should be safe, acceptable, simple, cheap, sensitive, specific and reliable [6]. Although the 75-g oral glucose tolerance test represents the gold standard for diagnosing dysglycaemia, it is hardly acceptable, simple or cheap for routine use. In this report, we develop, validate and evaluate a simple approach to screening for dysglycaemia that employs data from a brief history, physical examination, routine nonfasting laboratory studies and a random capillary glucose test.

\section{Methods}

To assess the likelihood of dysglycaemia, we developed a predictive equation using data from 1032 Egyptian subjects without a history of diabetes who participated in the Diabetes in Egypt Project between July 1992 and October 1993 [8]. The project was approved by the Egyptian Ministry of Health, the US Agency for International Development and the University of Michigan Institutional Review Board. All subjects provided informed consent. On the first visit, all subjects were assessed for age, sex, post-prandial time (self-reported number of hours since last food or drink other than water), family history of diabetes and random capillary whole blood glucose. On a separate day, height, weight, waist circumference, systolic and diastolic blood pressure, fasting total cholesterol, triglycerides, high-density lipoprotein (HDL), fasting plasma glucose (FPG) and plasma glucose $2 \mathrm{~h}$ after a 75 -g oral glucose load (2-h PG) were measured. Random capillary whole blood glucose was measured using a portable reflectance meter (One Touch II, LifeScan Inc., Milpitas, CA, USA). FPG, 2-h PG and lipids were measured using a Kodak Ektachem DT60II analyser (Eastman Kodak Co., Rochester, NY, USA).

Bivariate logistic regression analysis and stepwise selection procedures were used to select the best possible multivariate model from a panel of risk factors that are available in routine clinical practice. The panel included age, sex, BMI, waist circumference, hip circumference, systolic blood pressure, diastolic blood pressure, total cholesterol, HDL, low-density lipoprotein (LDL), triglycerides, post-prandial time, random capillary plasma glucose and family history of diabetes. Multiple logistic regression analysis was then used to develop an equation to predict dysglycaemia based on FPG $\geq 6.1 \mathrm{mmol} / 1$ and/or 2 -h $P G \geq 7.8 \mathrm{mmol} / \mathrm{l}$. Risk factors in the final model included age (years), sex (female), body mass index (BMI) calculated as weight in $\mathrm{kg}$ divided by height in meters squared $\left(\mathrm{kg} / \mathrm{m}^{2}\right)$, post-prandial time $(0-8+\mathrm{h})$, systolic blood pressure $(\mathrm{mmHg}), \mathrm{HDL}(\mathrm{mmol} / \mathrm{l})$ and random capillary plasma glucose $(\mathrm{mmol} / \mathrm{l})$. Capillary plasma glucose values were calculated by multiplying capillary whole blood glucose values by 1.14. Age, BMI, systolic blood pressure, HDL and capillary plasma glucose were modelled as continuous variables; post-prandial time was modelled as a continuous variable between 0 and $8 \mathrm{~h}$ (after which random capillary glucose did not vary as a function of post-prandial time); and sex was modelled a categorical variable $(0=$ male and $1=$ female $)$. The final mathematical equation provides an estimate of a subject's likelihood of dysglycaemia expressed as a probability between 0.0 and 1.0 .

The methodology and model-building process are described in detail elsewhere [9]. Briefly, descriptive statistics were obtained for all variables. We assessed multicollinearity and the linearity assumption for logistic regression equation. Accuracy, reliability and precision of regression coefficients were assessed by calculating the number of events per variable (EPV), the ratio of the number of outcome events to the number of predictor variables $[10,11]$. In general, the validity of a logistic regression equation becomes problematic when the EPV is $<10$. The possible interactions among variables were assessed using the Breslow and Day $\chi^{2}$ test [12].

The -2 Log Likelihood Ratio test was used to test the overall significance of the predictive equation. The significance of the variables in the model was assessed by the Wald $\chi^{2}$ test, estimated odds ratios and $95 \%$ confidence intervals. The fit of the model was assessed by the Hosmer-Lemeshow goodness of fit $\chi^{2}$ test $[13,14]$.

To select the optimal cut-point to define a positive test, a receiver operating characteristic (ROC) curve was constructed by plotting sensitivity against the false positive rate (1-specificity) over a range of cut-point values. We purposefully selected a cutpoint on the ROC curve to ensure a specificity of approximately $90 \%$. To assess the ability of the equation to predict outcome for study subjects, sensitivity, specificity, positive predictive value (PPV), and the odds of being affected given a positive result (OAPR) were calculated.

Concordance and discordance values, derived from the logistic regression analysis, were used to measure the association of predicted probabilities and check the ability of the equation to predict outcome. To evaluate the overall performance of the equation, we considered several measures of predictive performance including discrimination (quantified by the area under the ROC curve) and calibration (quantified by calibration slope) [15-20].

To validate the equation, we randomly divide the data set into two equal parts-a derivation (training) set and a validation (confirmatory) set. The equation was developed and estimated on the derivation set and tested and validated on the confirmatory set using a cross-validation procedure. The average performance was then calculated over two repetitions.

To compare the results obtained with the predictive equation and the results obtained with various recommended and proposed random capillary plasma glucose cut-points, we applied the equation and those cut-points to the validation (confirmatory) dataset. All statistical analyses were performed using SAS software version 6.12 (SAS Institute, Cary, NC, USA).

\section{Results}

Table 1 describes the characteristics of the subjects divided into derivation and validation sets. Figure 1(a) shows the distribution of study population by reported post-prandial time $(\mathrm{h})$. Figure $1(\mathrm{~b})$ shows median random plasma glucose 
Table 1 Characteristics of the study populations

\begin{tabular}{|c|c|c|c|}
\hline Variable & $\begin{array}{l}\text { Derivation } \\
\text { subjects } \\
n=516\end{array}$ & $\begin{array}{l}\text { Validation } \\
\text { subjects } \\
n=516\end{array}$ & $\begin{array}{l}\text { Total } \\
\text { population } \\
n=1032\end{array}$ \\
\hline $\begin{array}{l}\text { Age (years) } \\
\text { Mean (SD) }\end{array}$ & $44(15)$ & $45(14)$ & $45(15)$ \\
\hline $\begin{array}{l}\text { Sex (female) } \\
n(\%)\end{array}$ & $298(58)$ & $294(57)$ & $296(58)$ \\
\hline $\begin{array}{l}\text { BMI }\left(\mathrm{kg} / \mathrm{m}^{2}\right) \\
\text { Mean }(\mathrm{SD})\end{array}$ & $29.7(7.1)$ & $29.8(8.0)$ & $29.8(7.6)$ \\
\hline $\begin{array}{l}\text { Post-prandial time }(0-8+\mathrm{h}) \\
\text { Mean (SD) }\end{array}$ & $3(2)$ & $3(2)$ & $3(2)$ \\
\hline $\begin{array}{l}\text { Systolic blood pressure }(\mathrm{mmHg}) \\
\text { Mean (SD) }\end{array}$ & $130(23)$ & $129(22)$ & $130(23)$ \\
\hline $\begin{array}{l}\mathrm{HDL}(\mathrm{mmol} / \mathrm{l}) \\
\text { Mean (sD) }\end{array}$ & $1.2(0.5)$ & $1.2(0.5)$ & $1.2(0.5)$ \\
\hline $\begin{array}{l}\text { Capillary plasma glucose }(\mathrm{mmol} / \mathrm{l}) \\
\text { Mean (SD) }\end{array}$ & $5.9(2.3)$ & $6.2(2.7)$ & $6.1(2.5)$ \\
\hline $\begin{array}{l}\text { NGT }(2-\mathrm{h} \mathrm{PG}<7.8 \mathrm{mmol} / 1 \\
\text { and/or FPG }<6.1 \mathrm{mmol} / \mathrm{l}) \\
n(\%)\end{array}$ & $336(65)$ & $362(70)$ & $349(68)$ \\
\hline $\begin{array}{l}\mathrm{IGT}(2-\mathrm{h} P G \geq 7.8 \mathrm{mmol} / \mathrm{l}) \\
n(\%)\end{array}$ & $144(28)$ & $118(23)$ & $131(26)$ \\
\hline $\begin{array}{l}\text { IFG (FPG } \geq 6.1 \mathrm{mmol} / \mathrm{l}) \\
n(\%)\end{array}$ & $111(22)$ & 87 (17) & $99(20)$ \\
\hline $\begin{array}{l}\mathrm{DM}(2-\mathrm{h} \mathrm{PG} \geq 11.0 \mathrm{mmol} / \mathrm{l} \text { and } / \mathrm{or} \\
\mathrm{FPG} \geq 7.0 \mathrm{mmol} / \mathrm{l}) \\
n(\%)\end{array}$ & $77(15)$ & $58(11)$ & $68(13)$ \\
\hline
\end{tabular}

DM, diabetes mellitus; IFG, impaired fasting glucose; IGT, impaired glucose tolerance; NGT, normal glucose tolerance. levels (and $25-75 \%$ intraquartile ranges) by post-prandial time (h). Only $5 \%$ of the subjects were fasting (post-prandial time $\geq 8 \mathrm{~h}$ ). In general, RPG levels were highest $1-2 \mathrm{~h}$ postprandially and decreased thereafter $(P=0.003)$.

The predictive equation was calculated with the following logistic regression parameters: $P=1+1 /\left(1+\mathrm{e}^{-\mathrm{X}}\right)=$ where $\mathrm{X}=-8.3390+0.0214$ [age (years) $]+0.6764$ [if female] $+0.0335\left[\mathrm{BMI}\left(\mathrm{kg} / \mathrm{m}^{2}\right)\right]+0.0934$ [post-prandial time (hours)] +0.0141 [systolic blood pressure $(\mathrm{mmHg})]-0.0110$ [HDL $(\mathrm{mmol} / \mathrm{l})]+0.0243$ [random capillary plasma glucose $(\mathrm{mmol} /$ 1)]. Table 2 shows the maximum likelihood estimates for the logistic regression function. The overall significance of the equation by the $-2 \log$-likelihood test was $723.0(P=0.0001)$ with 7 degrees of freedom with $82 \%$ concordant pairs and $17.5 \%$ discordant pairs. The Hosmer-Lemeshow goodness of fit test was $7.98(P=0.44)$ with 8 degrees of freedom. The EPV was $159 / 7=23$. Because no interactions, either alone or in combination, added significantly to the equation, we did not add any of these parameters. No potential outliers were detected and the equation met the linearity assumption for logistic regression analysis.

The probability level that provided an optimal cut-point was 0.38 . Based on the classification table, derived from the
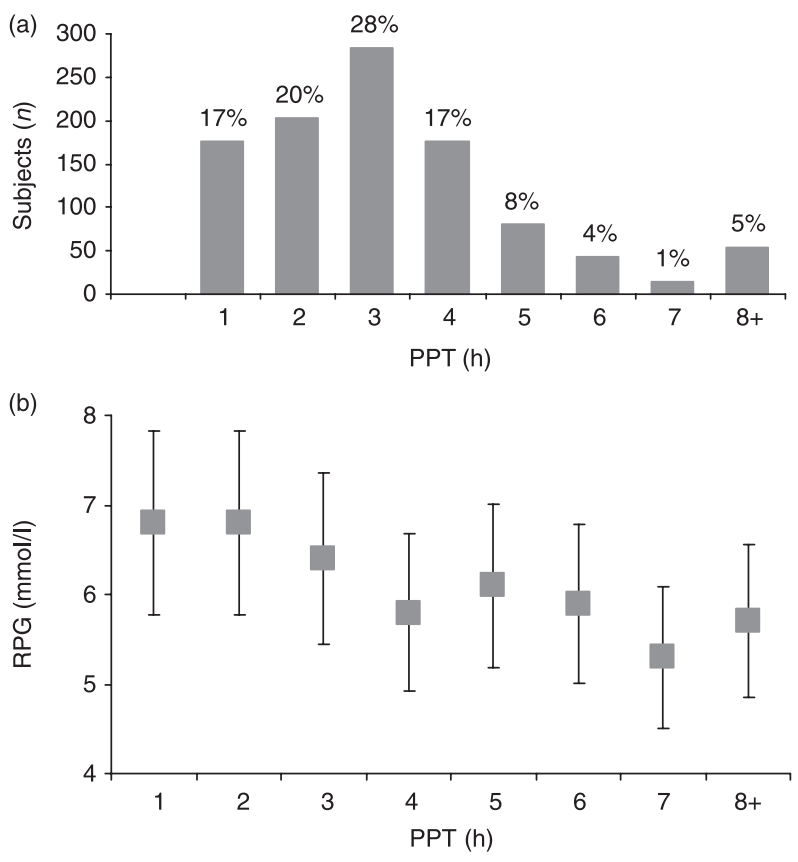

Figure 1 Distribution of study population by post-prandial time (a) and random plasma glucose (median and $25-75 \% \mathrm{IQR}$ ) by post-prandial time (b). 
Table 2 Maximum likelihood estimates of logistic regression function

\begin{tabular}{|c|c|c|c|c|c|c|}
\hline Variable & $\begin{array}{l}\text { Estimated } \\
\text { regression } \\
\text { coefficient }\end{array}$ & $\begin{array}{l}\text { Estimated } \\
\text { standard } \\
\text { error }\end{array}$ & Wald $\chi^{2}$ & $P$-value & $\begin{array}{l}\text { Estimated } \\
\text { odds ratio }\end{array}$ & $\begin{array}{l}95 \% \mathrm{CI} \\
\text { for OR }\end{array}$ \\
\hline Intercept & -8.3390 & \pm 0.739 & - & 0.0001 & - & - \\
\hline Age (years) & 0.0214 & \pm 0.008 & 7.5 & 0.006 & $1.24 *$ & $1.06-1.44 *$ \\
\hline Sex (female) & 0.6764 & \pm 0.213 & 10.1 & 0.002 & 1.97 & $1.30-2.99$ \\
\hline $\operatorname{BMI}\left(\mathrm{kg} / \mathrm{m}^{2}\right)$ & 0.0335 & \pm 0.013 & 6.2 & 0.01 & $1.03+$ & $1.01-1.06 \dagger$ \\
\hline Post-prandial time $(0-8 \mathrm{~h})$ & 0.0934 & \pm 0.053 & 4.3 & 0.04 & $1.10 \dagger$ & $1.01-1.21 \dagger$ \\
\hline Systolic blood pressure $(\mathrm{mm} / \mathrm{hg})$ & 0.0141 & \pm 0.005 & 9.4 & 0.002 & $1.15^{*}$ & $1.05-1.26^{*}$ \\
\hline $\mathrm{HDL}(\mathrm{mmol} / \mathrm{l})$ & -0.0110 & \pm 0.005 & 4.7 & 0.03 & 0.998 & $0.997-0.999 \ddagger$ \\
\hline Capillary plasma glucose $(\mathrm{mmol} / \mathrm{l})$ & 0.0243 & \pm 0.003 & 73.5 & 0.0001 & $1.28 *$ & $1.21-1.35^{*}$ \\
\hline
\end{tabular}

*Estimated ORs and 95\% CIs for 10 unit increase.

†Estimated ORs and $95 \%$ CIs for 1 unit increase.

‡Estimated ORs and $95 \%$ CIs for 0.1 unit increase.

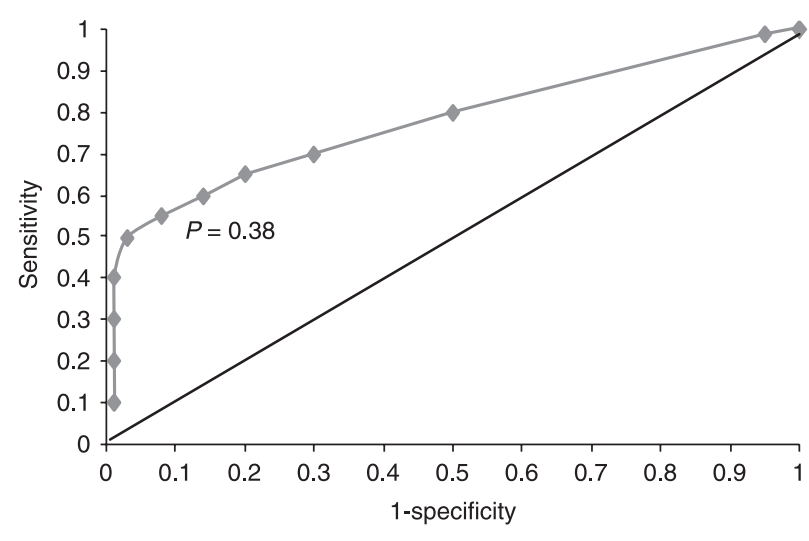

Figure 2 Receiver operator characteristic (ROC) curve. Points on the ROC curve represent the probability levels generated from the logistic regression analysis that was used to select the optimal cut-point. A probability value of 0.38 provided a sensitivity of $55 \%$ and a specificity of $90 \%$. The area under the ROC curve was 0.82 . Sensitivity and specificity of risk factors for the prediction of dysglycaemia were based on FPG $\geq 6.1 \mathrm{mmol} / 1$ and/or $2-\mathrm{h}$ PG $\geq 7.8 \mathrm{mmol} / 1$ and were estimated using the multiple regression model described in the text.

logistic regression and ROC curve analysis, sensitivity was $55 \%$, specificity $90 \%$ and PPV $65 \%$ (Fig. 2). The performance of screening test depends on the cut-point used to define a positive test. We chose the cut-point of 0.38 to optimize specificity. Choosing a probability level of 0.10 optimized sensitivity (sensitivity $91 \%$, specificity $39 \%$ and PPV 34\%). Choosing a probability of 0.22 produced equal sensitivity and specificity (sensitivity $73 \%$, specificity $73 \%$ PPV $49 \%$ ).

Screening tests that discriminate well between dysglycaemic and non-dysglycaemic individuals aggregate toward the upper left corner of the ROC curve. The area under the curve quantifies how well the screening test correctly distinguishes a dysglycaemic from a non-dysglycaemic person; the greater the area under the curve, the better the performance of the screening test. A diagonal reference line $(\mathrm{AUC}=0.50)$ defines points where a test is no better than chance in identifying persons with dysglycaemia. The area under the ROC curve was 0.82 . The calibration slope was 0.99 .

When applied to the validation sample, the equation's sensitivity was $53 \%$, specificity $89 \%$ and PPV $63 \%$. These represented relatively small decrements from the original equation.

When applied to the validation dataset with a $30 \%$ prevalence of dysglycaemia (the prevalence observed in the Egyptian dataset), the predictive equation and a cut-point of 0.38 performed better than static random capillary plasma glucose cut-points (Table 3). In general, the equation yielded higher sensitivity, identified more new cases (true positives) and missed fewer new cases (false negatives) than the static capillary plasma glucose cut-points $\geq 7.2, \geq 7.8, \geq 8.3, \geq 8.9 \mathrm{mmol} / \mathrm{l}$. The equation yielded higher specificity and identified fewer false positive cases than the static capillary plasma glucose cutpoints $\geq 5.0, \geq 5.6, \geq 6.1, \geq 6.7, \geq 7.2 \mathrm{mmol} / 1$. The equation yielded higher PPV than the static capillary plasma glucose cut-points $\geq 5.0, \geq 5.6, \geq 6.1, \geq 6.7, \geq 7.2, \geq 7.8 \mathrm{mmol} / \mathrm{l}$. The equation yielded higher OAPR than the static capillary plasma glucose cut-points $\geq 5.0, \geq 5.6, \geq 6.1, \geq 6.7, \geq 7.2 \mathrm{mmol} / 1$.

\section{Discussion}

Behavioural and pharmacological interventions can delay or prevent Type 2 diabetes in high risk populations [1-5,21]. In addition, emerging evidence suggests that earlier diagnosis and treatment of Type 2 diabetes may delay or prevent the development of complications [22]. Based on the results of these studies, it is likely that IFG and IGT will become targets for clinical and public health intervention. Currently, the diagnosis of dysglycaemia requires 2-h 75-g oral glucose tolerance tests. As has been amply documented, oral glucose tolerance tests are not commonly performed in routine clinical practice and alternative approaches to the diagnosis of dysglycaemia must be developed [23-27]. For these reasons, it is desirable to identify subpopulations at increased risk for dysglycaemia and develop quick, non-invasive and inexpensive methods of identifying individuals with dysglycaemia. 
Table 3 Comparison of the performance of the predictive equation and capillary plasma glucose cut-points for a hypothetical population of 1000 with a prevalence of IFG, IGT and undiagnosed diabetes of $30 \%$

\begin{tabular}{|c|c|c|c|c|c|c|c|}
\hline Screening test & $\begin{array}{l}\text { Sensitivity } \\
(\%)\end{array}$ & $\begin{array}{l}\text { Specificity } \\
(\%)\end{array}$ & $\begin{array}{l}\text { PPV } \\
(\%)\end{array}$ & $\begin{array}{l}\text { OAPR } \\
(+)\end{array}$ & $\begin{array}{l}\text { True } \\
(+)\end{array}$ & $\begin{array}{l}\text { False } \\
(-)\end{array}$ & False \\
\hline Equation & 53 & 89 & 63 & 2.06 & 159 & 77 & 141 \\
\hline \multicolumn{8}{|c|}{ Capillary plasma glucose: } \\
\hline$\geq 5.0 \mathrm{mmol} / \mathrm{l}$ & 94 & 21 & 25 & 0.51 & 282 & 553 & 18 \\
\hline$\geq 5.6 \mathrm{mmol} / \mathrm{l}$ & 90 & 36 & 29 & 0.60 & 270 & 448 & 30 \\
\hline$\geq 6.1 \mathrm{mmol} / 1$ & 73 & 67 & 39 & 0.95 & 219 & 231 & 81 \\
\hline$\geq 6.7 \mathrm{mmol} / 1$ & 57 & 82 & 48 & 1.35 & 171 & 126 & 129 \\
\hline$\geq 7.2 \mathrm{mmol} / 1$ & 46 & 88 & 55 & 1.64 & 138 & 84 & 162 \\
\hline$\geq 7.8 \mathrm{mmol} / 1$ & 40 & 95 & 71 & 3.43 & 120 & 35 & 180 \\
\hline$\geq 8.3 \mathrm{mmol} / 1$ & 37 & 97 & 83 & 5.29 & 111 & 21 & 189 \\
\hline$\geq 8.9 \mathrm{mmol} / 1$ & 35 & 98 & 85 & 7.50 & 105 & 14 & 195 \\
\hline
\end{tabular}

True positive $=$ new cases $=$ prevalence $\times$ sensitivity $\times n$; false positive $=1$-prevalence $\times 1$-specificity $\times n$; false negative $=$ missed cases $=$ prevalence $\times 1$-sensitivity $\times n$.

We have developed a multivariate predictive equation based on age, sex, BMI, post-prandial time, systolic blood pressure, HDL and capillary plasma glucose levels to access the likelihood of dysglycaemia. The equation was $55 \%$ sensitive and $90 \%$ specific. In validation testing, the equation was $53 \%$ sensitive and $89 \%$ specific. The relatively small decrement in sensitivity and specificity on validation testing suggest that the equation has both internal validity and generalizability [28].

A number of recent studies have suggested that risk factor questionnaires [29,30] and risk scores [25,31-36] can be used to screen for dysglycaemia and undiagnosed diabetes. The area under the ROC curves for the published risk scores have ranged from 0.66 to 0.74 for dysglycaemia and from 0.74 to 0.87 for undiagnosed diabetes. The performance of our equation to screen for dysglycaemia, with an area under the ROC curve of 0.82 , exceeds that for published risk scores for dysglycaemia and is comparable with published risk scores for undiagnosed diabetes. The sensitivity of the published risk scores have ranged from 51 to $69 \%$ for dysglycaemia and from 72 to $81 \%$ for undiagnosed diabetes. The specificity has ranged from 63 to $78 \%$ for dysglycaemia and 55 to $78 \%$ for undiagnosed diabetes. Compared with these risk scores, at the probability level of 0.38 , our equation is less sensitive $(55 \%)$ but more specific $(90 \%)$ than the risk scores for both dysglycaemia and undiagnosed diabetes.

The application of all screening tests requires a trade-off between sensitivity and specificity. If a lower cut-point value is used to define a positive test, sensitivity increases but specificity decreases. This results in more complete ascertainment of subjects with abnormal glucose tolerance, but substantially more false positive subjects who require follow-up diagnostic testing. The decision regarding acceptable levels of sensitivity and specificity involves weighing the consequences of leaving cases undetected (false negatives) and classifying healthy persons as abnormal (false positives) [37,38]. Highly sensitive tests are preferable if the failure to make an early diagnosis and initiate treatment has dire health consequences. Highly specific tests may be preferred if a disease is uncommon in the population or if a false positive result can harm the subject emotionally, physically or financially. In a substantial minority of subjects, dysglycaemia may revert to normal on follow-up testing [39-44]. In others, dysglycaemia may be slowly progressive but is not likely to be associated with short-term complications. For these reasons, and because dysglycaemia is an uncommon condition and follow-up diagnostic testing is potentially harmful, we believe that specificity should be optimized in screening. To avoid missing individuals with persistent or progressive dysglycaemia, it is imperative that periodic rescreening be performed.

Previously, using data from the same study, we developed an empirical formula to screen for undiagnosed diabetes [9]. The equation's sensitivity was $65 \%$ and its specificity was $96 \%$. Compared with the former equation, our present equation for dysglycaemia is less sensitive (55 vs. $65 \%$ ) and less specific $(90$ vs. $96 \%$ ). This indicates that the dysglycaemia equation does not work as well as the equation to predict undiagnosed diabetes. This may be due to the greater overlap of the distributions of random glucose levels between the normal and dysglycaemic populations (IFG, IGT and undiagnosed diabetes) compared with the population with undiagnosed diabetes. Other possible explanations include the variability, poor reproducibility and lack of test-to-test reliability of a 2-h PG of 7.8-11.0 $\mathrm{mmol} / 1$ for the prediction of IGT [39-44].

When we applied the equation for undiagnosed diabetes to predict dysglycaemia, our dysglycaemia equation was more sensitive (55 vs. $54 \%$ ) and more specific (90 vs. $84 \%$ ). This suggests that for the same outcome (prediction of dysglycaemia), the dysglycaemia equation works better than the equation for undiagnosed diabetes. It is likely that the inclusion of additional risk factors in the dysglycaemia equation (systolic blood pressure and HDL cholesterol) account for the improved performance.

Different ethnic groups may vary in their characteristics, which may affect a predictive equation's performance. It is 
important to assess the performance of the equation in different ethnic groups $[34,35,45,46]$. Indeed, some have suggested that ethnic group-specific cut-points may be needed for predictive equations [35]. We applied our predictive equation for undiagnosed diabetes [9], developed in the Egyptian population, to data from 1065 predominantly Caucasian-American subjects. The equation, which was $65 \%$ sensitive and $96 \%$ specific in the Egyptian population, was $62 \%$ sensitive and $96 \%$ specific in the US population. Thus, it performed well in another ethnic group. Although the variables included in the equation are routinely available for most adult patients in primary care in the United States, this may not be the case in other settings. This may limit the generalizability of the equation. Further evaluation of the dysglycaemia predictive equation in different populations is needed to further establish its generalizability.

In summary, by incorporating RPG data in combination with simple, available risk factor data, the predictive equation performs better in the general population than any single glucose cut-point. Although exhibiting a specificity of $\sim 90 \%$, use of the equation with a cut-point of 0.38 misses approximately $45 \%$ of persons with dysglycaemia. To avoid missing these 'false negative' screenees, it is imperative the repeat screening be performed periodically. The predictive equation has been designed to identify individuals at increased risk for dysglycaemia who require further diagnostic testing. The equation is designed to be used by primary care practitioners in general clinical practice. It can also be used by health systems with access to electronic medical records. The multivariate equation can be implemented with a number of inexpensive, programmable, hand-held calculators. We have programmed the formula and coefficients presented in the statistical methods section into a TI-83 graphic and scientific calculator (Dallas, TX, USA). To obtain a probability value, the user enters the values for age (years), systolic blood pressure $(\mathrm{mmHg})$, HDL $(\mathrm{mmol} / \mathrm{l})$, capillary plasma glucose $(\mathrm{mmol} / \mathrm{l})$, post-prandial time $(0-8+\mathrm{h})$, BMI $\left(\mathrm{kg} / \mathrm{m}^{2}\right)$ and sex ( 0 for male or 1 for female). The calculator prompts the user by displaying the coefficient for the variable that should be entered next. The result displayed is the calculated probability that a subject has dysglycaemia (a number between 0.0 and 1.0). The programming is available on request. Using this device and a glucose meter, a health-care professional can perform a quick point-of-care assessment of the probability of dysglycaemia to direct further definitive diagnostic testing.

\section{Competing interests}

None declared.

\section{Acknowledgements}

This work was supported by the US Agency for International Development and the Egyptian Ministry of Health under
PASA 236-0102-P-HI-1013-00; the Michigan Diabetes Research and Training Center under grant DK-20572; and US HHS-Centers for Disease Control and Prevention under grant MM-0345-03/03.

\section{References}

1 Pan XR, Li GW, Hu YH, Wang JX, Yang WY, An ZX et al. Effects of diet and exercise in preventing NIDDM in people with impaired glucose tolerance. The Da Qing IGT Diabetes Study. Diabetes Care 1997; 20: 537-544.

2 Tuomilehto J, Lindstrom J, Eriksson JG, Valle TT, Hamalainen H, Ilanne-Parikka P et al. Finnish Diabetes Prevention Study Group. Prevention of type 2 diabetes mellitus by changes in lifestyle among subjects with impaired glucose tolerance. N Engl J Med 2001; 344: 1343-1350.

3 The Diabetes Prevention Program Research Group. Reduction in the incidence of Type 2 diabetes with lifestyle modification or metformin. N Engl J Med 2002; 346: 393-403.

4 Buchanan TA, Xiang AH, Peters RK, Kjos SL, Marrogquin A, Goico $\mathrm{J}$ et al. Preservation of pancreatic beta-cell function and prevention of type 2 diabetes by pharmacological treatment of insulin resistance in high-risk Hispanic women. Diabetes 2002; 51: 2796-2803.

5 Chiasson JL, Josse RG, Gomis R, Hanefeld M, Karasik A, Laakso M, STOP-NIDDM Trial Research Group. Acarbose for prevention of type 2 diabetes mellitus: The STOP-NIDDM randomised trial. Lancet 2002; 359: 2072-2077.

6 Engelgau MM, Venkat Narayan KM, Herman WH. Screening for type 2 diabetes. Diabetes Care 2000; 23: 1563-1580.

7 Colagiuri S, Cull CA, Holman RR, The UKPDS Group. Are lower fasting plasma glucose levels at diagnosis of type 2 diabetes associated with improved outcomes. UK Prospective Diabetes Study 61 Diabetes Care 2002; 25: 1410-1417.

8 Herman WH, Ali MA, Aubert RE, Engelgau MM, Kenny SJ, Gunter EW et al. Diabetes mellitus in Egypt: risk factors and prevalence. Diabet Med 1995; 12: 1126-1131.

9 Tabaei BP, Herman WH. A multivariate logistic regression equation to screen for diabetes: development and validation. Diabetes Care 2002; 25: 1999-2003.

10 Peduzzi P, Concato J, Kemper E, Holford TR, Feinstein AR. A simulation study of the number of events per variable in logistic regression analysis. J Clin Epidemiol 1996; 12: 1373-1379.

11 Bagley SC, White H, Golomb BA. Logistic regression in the medical literature: standards for use and reporting, with particular attention to one medical domain. J Clin Epidemiol 2001; 54: 979-985.

12 SAS Institute Inc. SAS/STAT user's guide, Version 6, 4th edn Vol. 2. Cary, NC: SAS Institute Inc., 1990.

13 SAS Institute Inc. SAS/STAT Software. Changes and Enhancements Through Release of 6.12. Cary, NC: SAS Institute Inc., 1997.

14 Hosmer DW, Lemeshow S. Applied Logistic Regression, 2nd edn. New York, NY: Wiley \& Sons, 2000.

15 Steyerberg EW, Harrell FE, Jr, Borsboom GJJM, Eijkemans MJC, Vergouwe Y, Habbema JDF. Internal validation of predictive models: efficiency of some procedures for logistic regression analysis. J Clin Epidemiol 2001; 54: 774-781.

16 Altman DG, Royston P. What do we mean by validating a prognostic model? Statist Med 2000; 19: 453-473.

17 Steyerberg EW, Eijkemans MJC, Harrell FE, Jr, Habbema JDF. Prognostic modeling with logistic regression analysis: a comparison of selection and estimation methods in small data sets. Statist Med 2000; 19: 1059-1079.

18 Harrell FE, Jr, Lee KL, Mark DB. Multivariable prognostic models: issues in developing models, evaluating assumptions and adequacy, and measuring and reducing errors. Statist Med 1996; 15: 361-387. 
19 Justice AC, Covinsky KE, Berlin JA. Assessing the generalizability of prognostic information. Ann Intern Med 1999; 130: 515-524.

20 Steyerberg EW, Eijkemans MJC, Houwelingen JC, Lee KL, Habbema JD. Prognostic models based on literature and individual patient data in logistic regression analysis. Statist Med 2000; 19: 141-160.

21 American Diabetes Association and National Institute of Diabetes Digestive and Kidney Disease. The prevention or delay of type 2 diabetes. Diabetes Care 2002; 25: 742-749.

22 Herman WH, Engelgau MM. Commentary: screening for type 2 diabetes mellitus in asymptomatic adults. Clin Diabetes 2000; 18: 68.

23 Rolka DB, Narayan KMV, Thompson TJ, Goldman D, Lindenmayer $\mathrm{J}$, Alich $\mathrm{K}$ et al. Performance of recommended screening tests for undiagnosed diabetes and dysglycemia. Diabetes Care 2001; 24: 1899-1903.

24 Ealovega MW, Tabaei BP, Brandle M, Burke R, Herman WH. Opportunistic screening for diabetes in routine clinical practice. Diabetes Care 2004; 27: 9-12.

25 Stern MP, Williams K, Haffner SM. Identification of individuals at high risk of type 2 diabetes: do we need the oral glucose tolerance test? Ann Intern Med 2002; 136: 575-581.

26 Stolk RP, Grobbee DE, Orchard TJ. Why use the oral glucose tolerance test? Diabetes Care 1995; 18: 1045-1049.

27 Drash AL. Is the oral glucose tolerance test obsolete? Diabetes Care 1995; 18: 1072-1073.

28 Katz MH. Multivariable Analysis: a Practical Guide for Clinicians. Cambridge, UK: Cambridge University Press, 1999.

29 Ruige JB, de Neeling JN, Kostense PJ, Bouter LM, Heine RJ. Performance of an NIDDM screening questionnaire based on symptoms and risk factors. Diabetes Care 1997; 20: 491-496.

30 Burden ML, Burden AC. The American Diabetes Association screening questionnaire for diabetes. Is it worthwhile in the UK? Diabetes Care 1994; 17: 97.

31 Baan CA, Ruige JB, Stolik RP, Witteman JCM, Dekker JM, Heine RJ, Feskens EJM. Performance of a predictive model to identify undiagnosed diabetes in a health care setting. Diabetes Care 1999; 22: 213-219.

32 Lindstrom J, Tuomilehto J. The diabetes risk score: a practical tool to predict type 2 diabetes risk. Diabetes Care 2003; 26: 725-731.

33 Griffin SJ, Little PS, Hales CN, Kinmonth AL, Wareham NJ. Diabetes risk score: towards earlier detection of type 2 diabetes in general practice. Diabetes Metab Res Rev 2000; 16: 164-171.

34 Park PJ, Griffin SJ, Sargeant L, Wareham NJ. The performance of a risk score in predicting undiagnosed hyperglycemia. Diabetes Care 2002; 25: 984-988.
35 Spijkerman AMW, Yuyun MF, Griffin SJ, Dekker JM, Nijpels G, Wareham NJ. The performance of a risk score as a screening test for undiagnosed hyperglycemia in ethnic minority groups: data from the 1999 health survey of England. Diabetes Care 2004; 27: 116 122.

36 McNeely MJ, Boyko EJ, Leonetti DL, Kahn SE, Fujimoto WY. Comparison of a clinical model, the oral glucose tolerance test, and fasting glucose for prediction of type 2 diabetes risk in Japanese Americans. Diabetes Care 2003; 26: 758-763.

37 Fletcher RH, Fletcher SW, Wagner EH. Clinical Epidemiology: the Essentials, 3rd edn. Baltimore, MD: Williams \& Wilkins, 1996.

38 Hennekens CH, Buring JE. Epidemiology in Medicine. Boston, MA: Little Brown, 1987.

39 Shaw JE, Zimmet PZ, De Courten M, Dowse GK, Chitson P, Gareeboo $\mathrm{H}$ et al. Impaired fasting glucose or impaired glucose tolerance: what best predicts future diabetes in mauritius? Diabetes Care 1999; 22: 399-402.

40 Mooy JM, Gootenhuis PA, deVries H, Kostense PJ, Popp-Snijders C, Bouter LM et al. Intra-individual variation of glucose, specific insulin and proinsulin concentrations measured in two oral glucose tolerance tests in general Caucasian population. The Hoorn Study. Diabetologia 1996; 39: 298-305.

41 Eschwege E, Charles MA, Simon D, Thibult N, Balkau B. Reproducibility of the diagnosis of diabetes over a 30-month follow-up. The Paris Prospective Study. Diabetes Care 2001; 24: 1941-1944.

42 Burke JP, Haffner SM, Gaskill SP, Williams KL, Stern MP. Reservation from type 2 diabetes to nondiabetic status: influence of the 1997 American Diabetes Association criteria. Diabetes Care 1998; 21: $1266-1270$.

43 de Vegt F, Dekker JM, Stehouwer CD, Nijpels G, Bouter LM, Heine RJ. The 1997 American Diabetes Association criteria versus the 1985 World Health Organization criteria for the diagnosis of abnormal glucose tolerance: poor agreement in the Hoorn Study. Diabetes Care 1998; 21: 1686-1690.

44 Davidson MB, Peters AL, Schriger DL. An alternative approach to the diagnosis of diabetes with a review of the literature. Diabetes Care 1995; 18: 1065-1071.

45 UK Prospective Diabetes Study Group. UK prospective diabetes study XII. differences between Asian, Afro-Caribbean and White Caucasian type 2 diabetic patients at diagnosis of diabetes. Diabet Med 1994; 11: 670-677.

46 de Courten M, Zimmet P. Screening for non-insulin-dependent diabetes mellitus: where to draw the line. Diabet Med 1997; 14: 95-98. 